\title{
Die Autorinnen, die Autoren
}

Daniela Fuchs, geb. 1987, Humanökologin und Historikerin, wissenschaftliche Mitarbeiterin am Institut für Technikfolgen-Abschätzung der ÖAW. Forschungsschwerpunkte: Governance kontroverser Technologien, Nanotechnologien, Computermodellierung in der Politikberatung.

Jana Grusková, geb. 1970, Klassische Philologin, wissenschaftliche Mitarbeiterin am Institut für Mittelalterforschung, Abteilung Byzanzforschung, der ÖAW und Dozentin in Klassischer Philologie an der Comenius-Universität Bratislava.

Otto Kresten, geb. 1943, wirkliches Mitglied der ÖAW. Ab 1981 außerordentlicher Universitätsprofessor für Byzantinistik an der Universität Wien; 1982-1999 Direktor des Historischen Instituts beim Österreichischen Kulturinstitut in Rom; 1999 Rückkehr an die Universität Wien.

Gunther Martin, geb. 1976, Altertumswissenschaftler, habilitiert in Bern 2013, SNF-Professor in Klassischer Philologie an der Universität Zürich.

Michael Nentwich, geb. 1964, Dozent, Direktor des Instituts für Technikfolgen-Abschätzung der ÖAW. Forschungsschwerpunkte: Informationsgesellschaft, Internet und sein Einfluss auf Gesellschaft und Wissenschaft, Politikberatung und Parlament.

Herwig Wolfram, geb. 1934, em. o. Professor der Geschichte des Mittelalters, Direktor a. D. des Instituts für Österreichische Geschichtsforschung, wirkliches Mitglied der ÖAW, korrespondierendes Mitglied gelehrter Gesellschaften, Träger des Österreichischen Ehrenzeichens für Wissenschaft und Kunst. 
Der "Geistes-, sozial- und kulturwissenschaftliche Anzeiger" bringt Beiträge aus dem gesamten Spektrum der Geistes-, Sozial- und Kulturwissenschaften.

Informationen zum Ablauf der Manuskripteinreichung sowie Hinweise für die Gestaltung von Beiträgen finden Sie auf der Website http://epub.oeaw.ac.at/anzeiger 